Key Words:

$M C U$,

Solvent Extraction

Retention: Permanent

\title{
ANALYSIS OF SOLVENT RECOVERED FROM WRIGHT INDUSTRIES, INCORPORATED TESTING
}

\author{
Michael R. Poirier \\ Thomas B. Peters \\ Fernando F. Fondeur \\ Samuel D. Fink
}

January 11, 2006 
This document was prepared in conjunction with work accomplished under Contract No. DEAC09-96SRI8500 with the U. S. Department of Energy.

\section{DISCLAIMER}

This report was prepared as an account of work sponsored by an agency of the United States Government. Neither the United States Government nor any agency thereof, nor any of their employees, nor any of their contractors, subcontractors or their employees, makes any warranty, express or implied, or assumes any legal liability or responsibility for the accuracy, completeness, or any third party's use or the results of such use of any information, apparatus, product, or process disclosed, or represents that its use would not infringe privately owned rights. Reference herein to any specific commercial product, process, or service by trade name, trademark, manufacturer, or otherwise, does not necessarily constitute or imply its endorsement, recommendation, or favoring by the United States Government or any agency thereof or its contractors or subcontractors. The views and opinions of authors expressed herein do not necessarily state or reflect those of the United States Government or any agency thereof. 


\title{
ANALYSIS OF SOLVENT RECOVERED FROM WRIGHT INDUSTRIES, INCORPORATED TESTING
}

\author{
By Michael R. Poirier, Thomas B. Peters, Fernando F. Fondeur, and \\ Samuel D. Fink
}

\begin{abstract}
Washington Savannah River Company (WSRC) began designing and building a Modular Caustic Side Solvent Extraction (CSSX) Unit (MCU) at the Savannah River Site (SRS) to process liquid waste for an interim period. The MCU Project Team conducted testing of the contactors, coalescers, and decanters at Wright Industries, Incorporated (WII) in Nashville, Tennessee. That testing used MCU solvent and simulated SRS dissolved salt. Because of the value of the solvent, the MCU Project wishes to recover it for use in the MCU process in the H-Tank Farm. Following testing, WII recovered approximately 62 gallons of solvent (with entrained aqueous) and shipped it to SRS. The solvent arrived in two stainless steel drums. The MCU Project requested SRNL to analyze the solvent to determine whether it is suitable for use in the MCU Process.

SRNL analyzed the solvent for Isopar ${ }^{\circledR}$ L by Gas Chromatrography -Mass Spectroscopy (GC-MS), for Modifier and BOBCalixC6 ${ }^{1}$ by High Pressure Liquid Chromatography (HPLC), and for Isopar $^{\circledR}$ L -to-Modifier ratio by Fourier-Transform Infrared (FTIR) spectroscopy. They also measured the solvent density gravimetrically and used that measurement to calculate the Isopar ${ }^{\circledR} \mathrm{L}$ and Modifier $^{2}$ concentration.
\end{abstract}

The conclusions from this work follow.

- The constituents of the used WII solvent are collectively low in Isopar ${ }^{\circledR} \mathrm{L}$, most likely due to evaporation. This can be easily corrected through the addition of Isopar ${ }^{\circledR}$ L.

- Compared to a sample of the WII Partial Solvent (without BOBCalixC6) archived before transfer to WII, the Reworked WII Solvent showed a significant improvement (i.e., nearly doubling) in the dispersion numbers for tests with simulated salt solution and with strip acid. Hence, the presence of the plasticizer impurity has no detrimental impact on phase separation. While there are no previous dispersion tests using the exact same materials, the results seem to indicate that the washing of the solvent gives a dispersion benefit.

\footnotetext{
${ }^{1}$ BOBCalixC6 is an acronym for Calix[4]arene-bis(tert-octylbenzo-crown-6)

${ }^{2}$ Modifier, or Cs-7SB, are acronyms for (1-(2,2,3,3-tetrafluoropropoxy)-3-(4-sec-butylphenoxy)-2-propanol, CAS \# 308362-88-1
} 
- WII Solvent that underwent a cleaning cycle provides an acceptable set of cesium distribution (i.e., D) values when used in a standard Extraction, Scrub, and Strip (ESS) test.

\section{INTRODUCTION}

The Department of Energy identified the CSSX process as the preferred technology to remove cesium from radioactive waste solutions at the SRS. ${ }^{3,4}$ As a result, WSRC began designing and building a MCU in the SRS tank farm to process liquid waste for an interim period until the Salt Waste Processing Facility (SWPF) begins operations. The MCU Project Team conducted testing of the contactors, coalescers, and decanters at WII in Nashville, Tennessee. That testing used MCU solvent and simulated SRS dissolved salt.

Because of the value of the solvent, the MCU Project wishes to recover it for use in the process. Following testing, WII recovered approximately 62 gallons of solvent (including entrained aqueous) and shipped it to SRS. The solvent arrived in two stainless steel drums. The MCU Project requested SRNL to analyze the solvent to determine whether it is suitable for use in the MCU Process.

\section{ANALYSIS}

SRNL conducted the following analysis:

- GC-MS for Isopar ${ }^{\circledR} \mathrm{L}$

- HPLC for BOBCalixC6 and Modifier

- FTIR for Isopar ${ }^{\circledR}$ L-to-Modifier ratio

- Density

- A dispersion number test

- An extraction, scrub, strip (ESS) test to measure distribution coefficients during those process steps

GC-MS, HPLC, FTIR are standard methods used by SRNL's Analytical Labs. One of the authors measured the solvent density gravimetrically. They assumed that the density is a linear function of Isopar ${ }^{\circledR} \mathrm{L}$ and Modifier, and used the measured density to calculate those fractions.

SRNL conducted the dispersion number test in the following manner. Following the formal SRNL procedure, ${ }^{5}$ SRNL measured the dispersion numbers in four different systems. In short, the dispersion testing involves carefully layering an organic phase over an aqueous phase in a

\footnotetext{
${ }^{3}$ C. L. Huntoon to G. P. Rudy, memorandum titled "Preferred Alternative for the Savannah River Salt Processing Project", June 25, 2001.

${ }^{4}$ R. A. Dimenna, H. H. Elder, J. R. Fowler, R. C. Fowler, M. V. Gregory, T. Hang, R. A. Jacobs, P. K. Paul, J. A. Pike, P. L. Rutland, F. G. Smith III, S. G. Subosits, G. A. Taylor, S. G. Campbell, and F. A. Washburn, "Bases, Assumptions, and Results of the Flowsheet Calculations for the Decision Phase Salt Disposition Alternatives", WSRC-RP-99-00006, Rev. 3, May 24, 2001.

${ }^{5}$ Dispersion Number Testing for Aqueous-Organic Mixtures, I-WPT-012, Rev. 0, August 8, 2006.
} 
$100 \mathrm{~mL}$ graduated cylinder. The cylinder is capped and shaken in a consistent manner and the contents are then allowed to settle. The time from the end of the agitation to the point where the two phases cleanly separate is used to determine the dispersion number ${ }^{5}$ (equation 1 ).

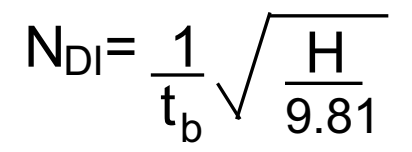

\section{Equation 1}

$\mathrm{N}_{\mathrm{DI}}$ is the dispersion number, $\mathrm{t}_{\mathrm{b}}$ is the time for the phases to separate in seconds, and $\mathrm{H}$ is the height of the $100 \mathrm{~mL}$ of total solution in the graduation cylinder, in meters.

SRNL conducted the ESS test per SRNL procedure, ${ }^{6}$ to measure the distribution coefficients for the used Wright solvent. The distribution tests involve contacting the solvent with several aqueous streams, the first of which contained a radioactive cesium spike. SRNL monitored the activity of the organic and aqueous phases throughout the test to determine the distribution of the radioactive cesium.

\section{RESULTS}

\section{Analysis of WII Solvent Drums}

Table 1 shows results of the analyses of the drums of solvent. The normalized concentration is the measured concentration divided by the target concentration. The analytical uncertainty associated with HPLC measurements is $10 \%$. GM-MS analytical uncertainty is $10 \%$ for Isopar ${ }^{\circledR}$ L. The variance ( $\%$ standard deviation) for the density measurements varied from sample to sample, but were all less than $0.4 \%$. There is no analytical uncertainty associated with the FTIR measurements.

The analysis of Drum 1 shows the solvent to have the correct composition. All of the measured components are within $6 \%$ of the target, except for the Isopar ${ }^{\circledR}$ L by GC-MS. We consider this result an analytical flier and not necessarily a problem with the method as a whole. In this case, we choose to use the Isopar ${ }^{\circledR} \mathrm{L}$ by density result. The analysis of Drum 2 shows that it is low in Isopar ${ }^{\circledR} \mathrm{L}$ and high in BOBCalixC6 and Modifier. The offsets from the expected values are likely due to evaporation losses of Isopar $^{\circledR} \mathrm{L}$. This drum could be recovered by adding additional Isopar ${ }^{\circledR}$ L. We recommend using density measurements to adjust the solvent due to the short measurement time.

SRNL mixed the two drums, collected a sample from each drum, combined the samples, "cleaned" the composite and filtered it (GF/F $15 \mathrm{~cm}$ glass filter disk). The material was then adjusted with added Isopar ${ }^{\circledR} \mathrm{L}$ (16.1\% volume increase), the amount of which was determined by successive density measurements as small increments of Isopar ${ }^{\circledR}$ L were added. Finally, SRNL

\footnotetext{
${ }^{6}$ Extraction, Scrub and Strip Testing of Solvent Extraction Systems, IWT-OP-143, Rev. 0, August 20, 2003.
} 
conducted dispersion number tests and ESS tests. Throughout the report, this solvent will be referred to as WII Reworked Solvent. SRNL derived the chemical cleaning program by analyzing results from previous work. ${ }^{7}$ SRNL performed the sample cleaning by contacting the solvent with scrub solution two times, followed by contacting the solvent with strip solution five times, and then contacting the solvent with wash solution one time. In each case, the O:A ratio was 5:1. Agitation was provided by gentle hand agitation for approximately 30 seconds, and the duration of contact was from several minutes (scrub and strip) to an hour (wash) depending on the phase separation time. SRNL used this washed solvent for the dispersion number test and the ESS test. An analysis of this reworked solvent indicates Diethyl hexyl phthalate (DEHP) is present at a concentration of approximately $1200 \mathrm{ppm}$. It may be possible to reduce the DEHP concentration through further cleaning.

Table 1. WII Solvent Analysis

\begin{tabular}{|c|c|c|c|c|}
\hline Analysis & Drum 1 & $\begin{array}{c}\text { Normalized } \\
\text { Concentration }\end{array}$ & Drum 2 & $\begin{array}{c}\text { Normalized } \\
\text { Concentration }\end{array}$ \\
\hline Density-target & 0.852 & & 0.852 & \\
\hline Density $\left(@ 25^{\circ} \mathrm{C}\right)$ & 0.855 & 1.00 & 0.884 & 1.04 \\
\hline Isopar ${ }^{\circledR}$ L -target & $69.1 \mathrm{wt} \%$ & & $69.1 \mathrm{wt} \%$ & \\
\hline Isopar $^{\circledR}$ L -density & $68.4 \mathrm{wt} \%$ & 0.990 & $61.3 \mathrm{wt} \%$ & 0.887 \\
\hline Isopar $^{\circledR}$ L -GC-MS & $58.4 \mathrm{wt} \%$ & 0.845 & $54.2 \mathrm{wt} \%$ & 0.784 \\
\hline Modifier-target & $29.8 \mathrm{wt} \%$ & & $29.8 \mathrm{wt} \%$ & \\
\hline Modifier-density & $30.5 \mathrm{wt} \%$ & 1.02 & $37.6 \mathrm{wt} \%$ & 1.26 \\
\hline Modifier-HPLC & $29.8 \mathrm{wt} \%$ & 1.00 & 36.8 wt $\%$ & 1.23 \\
\hline BobCalixC6-target & 0.938 wt $\%$ & & $0.938 \mathrm{wt} \%$ & \\
\hline BobCalixC6-HPLC & 0.939 wt $\%$ & 1.00 & $1.27 \mathrm{wt} \%$ & 1.35 \\
\hline $\begin{array}{c}\text { Isopar }{ }^{\circledR} \mathrm{L} / \text { Modifier- } \\
\text { target }\end{array}$ & 2.32 & 1 & 2.32 & 1 \\
\hline $\begin{array}{c}\text { Isopar }{ }^{\circledR} \mathrm{L} / \text { Modifier- } \\
\text { based on density }\end{array}$ & 2.24 & 0.971 & 1.63 & 0.704 \\
\hline $\begin{array}{c}\text { Isopar }{ }^{\circledR} \text { L /Modifier- } \\
\text { based on FTIR }\end{array}$ & 2.18 & 0.940 & 1.53 & 0.660 \\
\hline
\end{tabular}

\footnotetext{
${ }^{7}$ T. B. Peters, D. D. Walker, CSSX Solvent Cleaning and Analysis, SRNL-WPT-2005-00148, Rev. 0, December 13, 2005.
} 


\section{Dispersion testing on the WII Solvent}

SRNL tested four systems in a test series using two organic solutions vs. two aqueous solutions. The organic phases were WII Partial Solvent (solvent with no BOBCalixC6 used in earlier Wright testing ${ }^{8}$ ) and Reworked WII Solvent. The Partial Solvent is an archived sample not previously transferred to WII and hence free of any plasticizer (or DEHP) that contaminated the other solvent.

The aqueous solutions were Optima caustic salt solution (QAB-0533) ${ }^{9}$ and freshly-prepared strip solution ( $0.001 \mathrm{M}$ nitric acid). The salt solution is an archived sample of the material prior to testing at WII, hence free of any plasticizer (or DEHP) that contaminated the other solvent.

Table 2 shows the dispersion number test results.

\section{Table 2. Dispersion Testing Results}

\begin{tabular}{|c|c|c|c|c|}
\hline Solvent & $\begin{array}{c}\text { Organic } \\
\text { Volume }(\mathrm{mL})\end{array}$ & $\begin{array}{c}\text { Aqueous } \\
\text { Phase }\end{array}$ & $\begin{array}{c}\text { Aqueous } \\
\text { Volume (mL) }\end{array}$ & $\begin{array}{c}\text { Dispersion } \\
\text { Number }\end{array}$ \\
\hline WII Partial & 25 & Optima & 75 & $3.74 \mathrm{E}-04$ \\
\hline WII Partial & 83 & Strip Acid & 17 & $6.00 \mathrm{E}-04$ \\
\hline Reworked WII & 25 & Optima & 75 & $6.66 \mathrm{E}-04$ \\
\hline Reworked WII & 83 & Strip Acid & 17 & $1.12 \mathrm{E}-03$ \\
\hline
\end{tabular}

The dispersion number is a unit-less value; higher results indicate cleaner, faster phase separation and a more favorable outcome.

Compared to the WII Partial Solvent, the Reworked WII Solvent showed a significant improvement in the dispersion characteristics. There are no previous dispersion tests that used the exact same materials, but SRNL believes the absence of the BOBCalixC6 makes no difference in the dispersion results. Therefore the results indicate that the washing of the solvent gives superior phase separation characteristics.

\footnotetext{
${ }^{8}$ K. Adu-Wusu, F. F. Fondeur, T. L. White, and S. L. Crump, "Preparation of Caustic Side Solvent Extraction (CSSX) Solvent with no BOBCalixC6 to Wright Industries - Component Amounts and Analytical Results," SRNL-WPT-2005-00066, May 16, 2005.

${ }^{9}$ D. D. Walker, "Composition of Simulant for Modular Caustic-Side Solvent Extraction Unit (MCU) Contactor Testing," SRNL-WPT-2005-00063, May 12, 2005.
} 


\section{ESS Test Results on the Wright Solvent}

As part of a series of ESS tests, SRNL measured the distribution coefficients of the Reworked WII Solvent.

Table 3 shows the ESS test results, corrected to the normal process operating temperatures (23 and $33{ }^{\circ} \mathrm{C}$ respectively for extraction and scrubbing, stripping). ${ }^{10}$ Table 3 also includes results from a prior SRNL test set that used a comparable salt solution and pristine solvent produced by Oak Ridge National Laboratory personnel. ${ }^{11}$

Table 3. ESS Cesium Distribution Values for the Reworked WII Solvent

\begin{tabular}{|l|c|c|c|c|c|c|}
\hline Step & Extraction & Scrub \#1 & Scrub \#2 & Strip \#1 & Strip \#2 & Strip \#3 \\
\hline $\begin{array}{l}\text { Acceptable } \\
\text { Range }\end{array}$ & $>8$ & $>0.6,<2$ & $>0.6,<2$ & $<0.2$ & $<0.16$ & $<0.16$ \\
\hline $\begin{array}{l}\text { Reworked } \\
\text { Solvent }\end{array}$ & 9.39 & 1.97 & 1.38 & 0.0573 & 0.0388 & 0.0357 \\
\hline $\begin{array}{l}\text { Prior } \\
\text { Comparable } \\
\text { Test }\end{array}$ & $12.2 \pm 0.2$ & $0.73 \pm 0.30$ & $0.94 \pm 0.37$ & $\begin{array}{c}0.055 \pm \\
0.015\end{array}$ & $\begin{array}{c}0.074 \pm \\
0.026\end{array}$ & $\begin{array}{c}0.094 \pm \\
0.055\end{array}$ \\
\hline
\end{tabular}

The tests show acceptable D values for each step of the process, although the measured D values for the extraction are not as good as evidenced in past tests with fresh solvents. The authors speculated that the cleaning cycle may have not completely removed Cs, potassium or other contaminants from the solvent from the WII testing and solvent recovery activities. The good cesium distribution values during the strip portion of the test suggest that the solvent improved after the additional scrub and strip operations.

Researchers performed a second, partial washing cycle and then repeated the extraction step of the ESS test (Table 4). SRNL took the residual organic phase from the first WII ESS test and contacted it with $0.001 \mathrm{M}$ nitric acid (strip solution, in a 1:3 O:A ratio) for 3 hours before using it in an abbreviated ESS test consisting of only the initial extraction contact.

Table 4. Extraction D Value for the Second WII ESS Test

\begin{tabular}{|l|c|}
\hline Step & Extraction \\
\hline D Value & 16.0 \\
\hline
\end{tabular}

\footnotetext{
${ }^{10}$ L. H. Delmau, J. F. Birdwell Jr, P. V. Bonnesen, L. J. Foote, T. J. Haverlock, L. N. Klatt, D. D. Lee, R. A. Leonard, T. G. Levitskaia, M. P. Maskarinec, B. A. Moyer, F. V. Sloop Jr, B. A Tomkins, "Caustic Side Solvent Extraction: Chemical and Physical Properties of the Optimized Solvent”, ORNL/TM-2002/190, October 2002.

${ }^{11}$ D. D. Walker, "Performance Testing of Parsons Solvent Sample," SRNL-WPT-2005-00085, July 29, 2005.
} 
There is a large increase in the D values in the extraction tests between the two extraction tests indicating possible improved performance after further stripping. However, the D value calculation is sensitive to small changes in the initial cesium activity as well as small changes in the distribution between the organic and aqueous phases. If the activities (dpm) of the second Wright test are normalized to those of the first WII test (the second test was run on a smaller scale), the amounts of activity in the respective aqueous and organic phases are within $10 \%$ of each other. Even though the change in D values does not absolutely imply improved performance as a function of further washing, SRNL still recommends a washing strategy.

\section{CONCLUSIONS}

The conclusions from this work follow.

- The constituents of the used WII solvent are collectively low in Isopar ${ }^{\circledR} \mathrm{L}$, most likely due to evaporation. This can be easily corrected through the addition of more Isopar ${ }^{\circledR} \mathrm{L}$.

- The WII solvent returned from the Integrated Testing would require a decant of the water in the bottom of the drums prior to addition of the $\operatorname{Isopar}^{\mathbb{B}} \mathrm{L}$ for adjustment.

- Compared to a sample of the WII Partial Solvent (without BOBCalixC6) archived before transfer to WII, the Reworked WII Solvent showed a significant improvement (i.e., nearly doubling) in the dispersion numbers for tests with simulated salt solution and with strip acid. Hence, the presence of the plasticizer impurity has no detrimental impact on phase separation. While there are no previous dispersion tests using the exact same materials, the results seem to indicate that the washing of the solvent gives a dispersion benefit.

- Reworked WII Solvent that underwent a cleaning cycle provides an acceptable set of cesium distribution (i.e., D) values when used in a standard Extraction, Scrub, and Strip (ESS) test. 